\title{
Risk factors for progressive visual field loss in primary open angle glaucoma
}

PGD Spry, JM Sparrow,

JP Diamond and HS Harris

\section{Abstract}

Purpose The aim of this study was to evaluate routine ophthalmic data to identify clinically useful risk factors for progressive visual field loss in patients with primary openangle glaucoma (POAG) already receiving intraocular pressure-lowering treatments. Methods A retrospective cohort study design was used. Routine ophthalmic data for all subjects were obtained from case records with the knowledge that baseline clinical data had been collected in a standardised manner. Progression was defined according to the AGIS visual field defect scoring system. Variables evaluated as candidate risk factors for progression were assessed by survival analysis. Factors exerting a significant effect on survival were subsequently tested in a Cox proportional hazards model.

Results A cohort of 108 eligible POAG patients was followed over an average of 3.6 years, with an average visual field intertest interval of 8 months. The incidence rate of progressive loss among the cohort was 5.4 cases per 100 person years. Increasing age was found to be independently associated with a small but significantly increased risk of glaucomatous visual field defect progression (hazard ratio 1.07, $P=0.022$ ), and a borderline association was also demonstrated with being male (hazard ratio $2.76, P=0.057$ ).

Conclusions This retrospective investigation has provided preliminary information on factors associated with increased risk of progressive glaucomatous visual field loss that may inform clinical care strategies. Lack of concordance with other studies suggests that further prospective investigations are needed if risk stratification strategies are to be employed in caring for patients with chronic open-angle glaucoma.
Eye (2005) 19, 643-651. doi:10.1038/sj.eye.6701605

Published online 11 June 2004

Keywords: glaucoma; progression; visual field; risk factors; cohort study

\section{Introduction}

Considerable clinical and epidemiological research efforts have been directed towards the identification of early primary open-angle glaucoma (POAG). This has resulted in increased knowledge of risk factors for development of glaucoma, ${ }^{1-8}$ signs associated with glaucomatous optic nerve damage, characteristics of glaucomatous loss of visual function, ${ }^{9-13}$ and consequently optimised decision-making strategies for discrimination between normal individuals and those with POAG. ${ }^{14-16}$

Once an individual has been diagnosed with POAG, intraocular pressure-lowering treatment is commenced with the aim of preventing or decelerating progressive loss of visual function. Patients who receive treatment require lifelong follow-up to monitor the effectiveness of this intervention. Glaucoma follow-up therefore requires considerable healthcare resource and it has been estimated to account for approximately $25 \%$ of outpatient consultations within the Hospital Eye Service (HES). ${ }^{17}$

In clinical situations, the ability to identify individuals who have a higher likelihood of progressive glaucomatous damage is desirable to identify those patients who may require further treatment intervention. To date, a number of investigators have studied prognostic factors associated with progressive normal-tension glaucoma, ${ }^{14,18-21}$ but limited attempts have been made to identify risk factors for progressive POAG in treated patients..$^{22-24}$

The aim of this study was to evaluate routine ophthalmic data to identify clinically useful risk
Bristol Eye Hospital

Bristol, England

Correspondence: PGD Spry

Bristol Eye Hospital Lower Maudlin Street Bristol BS1 2LX, England Tel: + 0441179284652 Fax: +044179284891

E-mail: paul.spry@ ubht.swest.nhs.uk

Received: 15 October 2003 Accepted: 29 March 2004; Published online: 11 June 2004

PGDS received support for this project from the Charitable Trust for the United Bristol Hospitals Interests: None of the authors have any commercial interest in any equipment or medication used in the course of this study 
factors for progressive visual field loss in patients with POAG already receiving intraocular pressure-lowering treatments.

\section{Methods}

\section{Study design}

A retrospective (historical) cohort study design was used. Case-notes from all individuals attending routine consultant-led outpatient glaucoma clinics staffed by one glaucoma clinician at Bristol Eye Hospital during a 37week period (May 2001 to January 2002) were reviewed and individuals that met predefined eligibility criteria (Table 1) were included. Patients attending these clinics were not preselected in any way other than requiring review for chronic glaucoma. Case notes from the time of recruitment back to baseline assessment were obtained. For the purposes of this study a clinical case-note diagnosis of POAG was used, rather than a strict definition set by the investigators. POAG was therefore defined pragmatically according to characteristic glaucomatous optic nerve head appearance and/or glaucomatous visual field defects (GVFD) in the presence of untreated intraocular pressures $\geq 22 \mathrm{~mm} \mathrm{Hg}$ in either eye and gonioscopically open anterior chamber angles.

Study data were obtained from the routine clinical case-notes of eligible POAG patients and entered into a database for storage. Standardised clinical assessment and data recording has been performed at the initial evaluation of all new referrals for suspected glaucoma at Bristol Eye Hospital since 1996. Uniform baseline data were thus available for this study. These data were recorded on a specifically designed proforma producing a high level of information completeness. Longitudinal data comprised routine clinical observations made regularly during normal clinical follow-up.

\section{Case definition}

The outcome, progressive glaucomatous visual field loss, was defined using the visual field defect scoring system developed by the Advanced Glaucoma Intervention Study (AGIS). This scoring system is complex and is described in detail elsewhere. ${ }^{25}$ Briefly, a test result from Program 24-2 of the Humphrey Field Analyzer (HFA) is assigned a score on a 21 point ordinal scale using the integers 0 (no defect) to 20 (severely defective) based on both the extent and depth of clusters of adjacent depressed test locations relative to age-matched normal data. Progression was defined according to the described $95 \%$ test-retest reliability of this scale as a change of 4 or more intervals from baseline ${ }^{25}$ confirmed on retest. ${ }^{26,27}$ For all subjects, the first visual field test performed was disregarded and the second test result was used as the study baseline field in order to decrease the impact of any visual field 'learning effect ${ }^{28}$ and therefore maximise the validity of the baseline visual field score.

\section{Risk Factors for progressive glaucomatous visual field loss}

Exposures considered as candidate risk factors for progressive visual field loss are given in Table 2. It is important to note that the retrospective cohort design limits the ascertainment of risk factors to those exposures routinely recorded. Exposures included were selected on the basis of association with development of chronic open-angle glaucoma in peer-reviewed literature. ${ }^{1-8,29-42}$ Some exposures were 'by patient' while others were 'by eye'. Exposures were either be derived from baseline characteristics, for example, the presence of $\alpha$ or $\beta$ parapapillary atrophy, or were obtained from sequential measurements made during routine clinical review, such as IOP variation during the study.

\section{Statistical analysis}

Analysis was performed by eye, with one eye included from each subject. In subjects with unilateral visual field defect progression, data pertaining to the eye exhibiting progressive loss were selected for subsequent analysis.

Table 1 Eligibility criteria

\begin{tabular}{ll}
\hline Inclusion criteria Exclusion criteria & Exila
\end{tabular}

Diagnosed POAG ${ }^{\mathrm{a}}$

Four or more visual field test results Assessment with HFA Program 24-2 Reliable perimetric observer
All other glaucomas (including pseudoexfoliative, pigmentary and normal tension glaucomas ${ }^{\mathrm{b}}$ )

Coexistent ocular or systemic pathology known to produce visual field defects Ocular or systemic medications likely to produce visual field defects Inadequate case-note information

a Based on a pragmatic decision including visual field status and optic nerve head appearance made by the monitoring clinician, but always included a pretreatment IOP measurement of $\geq 22 \mathrm{mmHg}$ on one or more occasions.

${ }^{\mathrm{b}}$ Based on a pragmatic decision including visual field status and optic nerve head appearance made by the monitoring clinician, with IOP measurement remaining $\leq 21 \mathrm{mmHg}$ on all occasions.

${ }^{c}$ False positives and negatives $<33 \%$ and fixation losses $<25 \%$ at each visual field test. 
Table 2 Exposures assessed as candidate risk factors using survival analysis

\begin{tabular}{|c|c|c|}
\hline Treatment-related factors & Other clinical factors & Demographic and historical factors \\
\hline Maximum recorded IOP $(\mathrm{mmHg})$ & Baseline cup-to-disc ratio ${ }^{a}$ & Age at baseline \\
\hline $\begin{array}{l}\text { IOP reduction, }(\%) \\
\text { (mean prestudy IOP vs. mean study) }\end{array}$ & $\begin{array}{l}\text { Baseline visual field status } \\
\text { (AGIS score) }\end{array}$ & Sex \\
\hline $\begin{array}{l}\text { IOP variation during study (standard } \\
\text { deviation) }\end{array}$ & $\begin{array}{l}\text { Visual field loss within } 5^{\circ} \text { of } \\
\text { fixation at baseline }\end{array}$ & High myopia(worse than -5.00 dioptres) \\
\hline \multirow[t]{4}{*}{ Treatment duration } & Parapapillary atrophy $(\alpha$ or $\beta)$ & Positive family history of chronic glaucoma \\
\hline & Disc haemorrhage during study & Diabetes $^{\mathrm{b}}$ \\
\hline & & Systemic hypertension ${ }^{\mathrm{b}}$ \\
\hline & & $\begin{array}{l}\text { Possible vasospasm }{ }^{\mathrm{b}} \\
\text { (history of migraine and/or cold extremities) }\end{array}$ \\
\hline
\end{tabular}

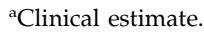

belf-reported.

For subjects found to have bilateral progression or no progression, data from one eye were randomly selected for inclusion in the analysis. Randomisation was achieved using a binary random number generator on a personal computer.

Survival analysis was performed to assess the association between each exposure (candidate risk factor) and outcome. Hypothesis testing was performed using the log rank test for the equality of survivor functions. Where necessary, continuous variables were arbitrarily converted to ordinal variables for this component of the analysis. Candidate exposures that were found to exert most significant effects in the log-rank test were then tested in a Cox proportional hazards model. The proportional hazards assumption was checked graphically prior to modelling and again after modelling by using a test based on the residuals. ${ }^{43}$ All analysis was performed using Intercooled Stata version 7.0 (College Station, TX, USA).

\section{Results}

The case-notes of 651 patients were reviewed and of these 108 met the criteria for recruitment. Of the 453 not included, the reasons for noninclusion are given in Figure 1. The distribution of age, sex, and AGIS scores among the 13 individuals excluded from analysis because of incomplete case-note data were broadly similar to the population studied.

Summary descriptive data for the cohort are provided in Table 3. The mean (standard deviation) duration of follow-up for the 108 eligible subjects was 3.6 (1.3) years. For the entire cohort IOP was found to be on average $19.5 \%$ lower over the course of the study compared with mean pretreatment levels measured within our institution: average 'on-treatment' IOP during the study

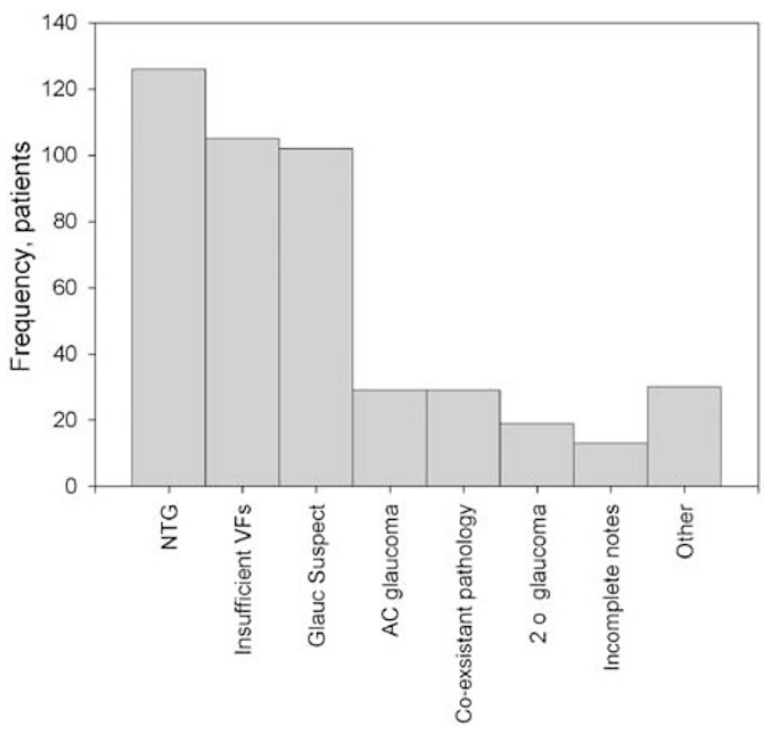

Figure 1 Histogram reasons for clinical case notes reviewed ( $n=651)$ but found to be ineligible $(n=453)$ for the study (NTG = normal tension glaucoma; $\mathrm{VFs}=$ visual fields; $\mathrm{AC}=$ angle closure; $2 \mathrm{o}=$ secondary; other $=$ patients with nonglaucomatous ocular pathologies erroneously booked into glaucoma clinic).

was 17.5 (3.2) $\mathrm{mmHg}$. The mean IOP during the study was $16.5(2.6)$ and $17.8(3.2) \mathrm{mmHg}$ for the progressive and nonprogressive groups, respectively, with no significant IOP difference existing between these groups $(P=0.106$, unpaired $t$-test).

Over the course of the study, visual field tests were performed, on average, every 8 months. There was no significant difference in the average number of tests performed by individuals who progressed and those who did not $(P=0.265$, Rank Sum Test). On average (standard deviation), 5.7 (1.6) and 5.3(1.5) visual field tests were performed per subject during this period for 
Table 3 Sample distribution or prevalence of exposures assessed as candidate risk factors

\begin{tabular}{lc}
\hline Variable & Value \\
\hline Mean (SD) baseline age, years & 71 (11.1) \\
Male: female ratio & $56: 52$ \\
Sample prevalence of high myopia (cases) & 15 \\
Sample prevalence of glaucoma family history (cases) & 37 \\
Sample prevalence of diabetes (cases) & 13 \\
Sample prevalence of hypertension (cases) & 31 \\
Sample prevalence of possible vasospasm (cases) & 36 \\
Mean (SD) baseline cup-to-disc ratio & 0.65 (0.20) \\
Mean (SD) baseline AGIS score & 3.3 (4) \\
Sample prevalence of visual field loss with 5 of fixation (cases) & 48 \\
Sample prevalence of parapapillary atrophy (cases) & 31 \\
Sample prevalence of disc haemorrhage (cases) & 7 \\
Mean (SD) maximum recorded pre-treatment intraocular pressure, mmHga & 25.6 (5.8) \\
Mean (SD) IOP reduction, \% (mean pre-study IOP vs. mean study IOP) & 19.5 (17.1) \\
Mean (SD) IOP variation during study (SD of IOP measurements) & 3.3 (1.5) \\
Mean (SD) treatment duration, months & 39.2 (17.6) \\
\hline
\end{tabular}

${ }^{a}$ Maximum IOP measurement made within Bristol Eye Hospital prior to treatment intervention. This measurement did not include IOP level by referring optometrist.

the nonprogressing and progressing subgroups respectively.

In all, 19 individuals (17.6\%) demonstrated progressive glaucomatous visual field loss during the study and in 15 cases this was found to be unilateral (eight right and seven left eyes). The sample incidence rate of progressive glaucomatous visual field loss was calculated to be 5.4 cases per 100 person years.

Survival analysis using exposures considered as candidate risk factors for visual field defect progression suggested that progression is most likely to be associated with increasing age $(P=0.056)$, male sex $(P=0.025)$, and maximum recorded IOP exceeding $32 \mathrm{mmHg}$ at any time during the course of follow-up $(P=0.011)$, and KaplanMeier survival curves for these variables are shown in Figure 2. It should be noted that black race was not assessed by survival analysis due to the small number of black people in the sample. As there were only 19 patients with the outcome of glaucomatous visual field defect progression, no more than three variables could be considered in a multivariate Cox proportional hazards model for statistical reasons, and therefore only those with the most significant associations, age, maximum measured IOP, and sex were included. The results of the Cox model are provided in Table 4 and demonstrated that while there was a trend toward men being at 2.76 times greater risk of progressive visual field loss than women, in the multivariate model this trend did not reach significance at the $P<0.05$ level $(P=0.057)$.

However, a significant increase in likelihood of progression (hazard ratio) was found with increasing age $(P=0.022)$. The hazard ratio for this variable was 1.07 (95\% confidence interval (CI) 1.01-1.12), which may be interpreted as a $7 \%$ increase in risk for each additional year of age within the cohort range (40-87 years). Cox modelling also suggested a trend whereby higher IOPs appeared associated with greater likelihood of progression. The hazard ratio for this variable was 1.07 (95\% CI 0.99-1.15), implying a 7\% increase in risk of progression for each additional $\mathrm{mmHg}$ within the cohort range $(22-45 \mathrm{mmHg})$.

\section{Discussion}

In our institution information on many clinical variables is collected during routine evaluation of glaucoma suspects and patients, especially during the initial 'baseline' clinical assessment. In this clinical context, baseline routine data are used primarily for assessing the risk of the individual having the disease glaucoma, on the basis of findings from a number of observational, mostly cross-sectional studies. ${ }^{1-3,7,8,31,40,41}$ As previously discussed conceptually by Drance $e t a l$, it is important to distinguish between factors that affect disease occurrence, that is, prevalence or incidence of new cases, and those that affect progression of existing glaucomatous damage. ${ }^{14}$ Factors associated with occurrence of glaucoma are important clinically to assist in 'case finding' or detection of disease, and are also of use from a public health perspective for health care service planning. However, risk factors associated with disease progression assist with estimation of prognosis for future development of clinically important visual morbidity and therefore inform aspects of treatment, including the aggressiveness of antiglaucoma interventions that can be justified and the required frequency of clinical follow-up appointments. Ultimately, detailed knowledge of prognostic factors may provide 
a

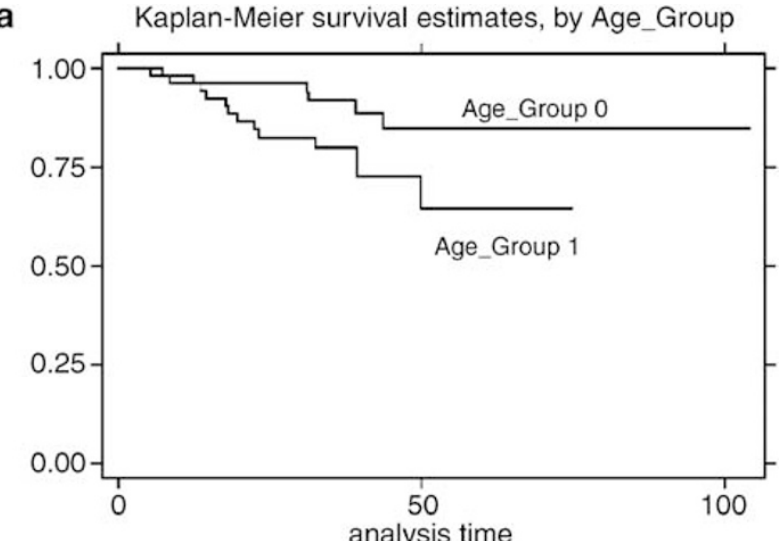

b

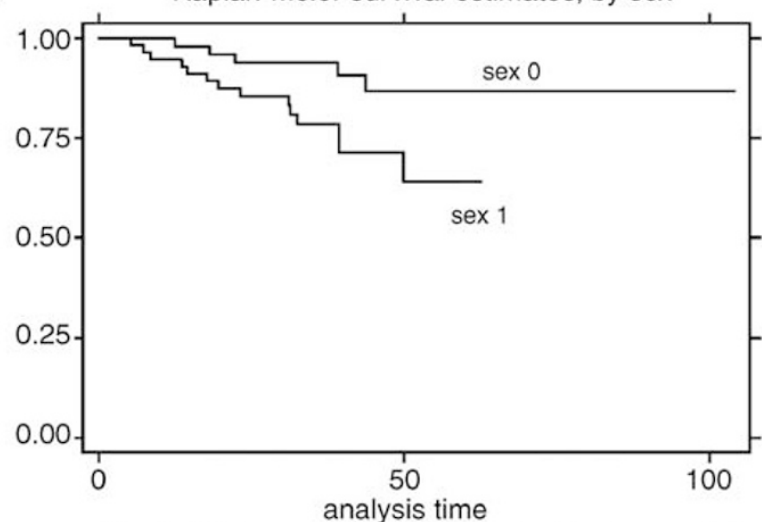

C

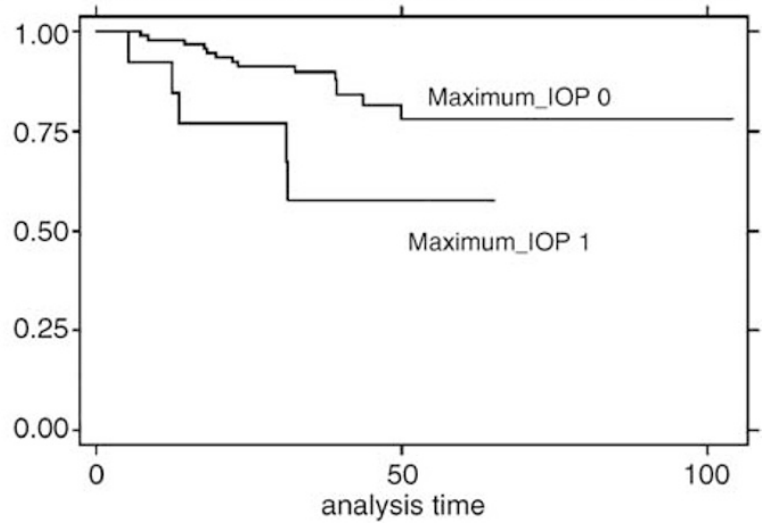

Figure 2 Kaplan-Meier survival curves for the three factors found to be associated with progressive GVFD. (a) Greater visual field survival in younger patients (Age_Group 0 comprises individuals of age $\leq 72$ years) than those of increasing age (Age_Group 1 comprises individuals of age $>72$ years). The sample was divided by age according to the median. (b) Visual field survival by sex. It can be observed that more males (sex 1) attain the outcome of visual field progression than females (sex 0 ) over the course of the study. (c) Effect of an IOP of $>32 \mathrm{mmHg}$ at any time over the course of the study (group 1) compared with subjects whose IOP was consistently below this level (group 0).
Table 4 Results of Cox proportional hazards model

\begin{tabular}{lcccl}
\hline $\begin{array}{l}\text { Exposure } \\
\text { (candidate risk } \\
\text { factor) }\end{array}$ & $\begin{array}{c}\text { Hazard } \\
\text { ratio }\end{array}$ & $\begin{array}{c}95 \% \\
(\mathrm{CI})\end{array}$ & P-value & Range \\
\hline $\begin{array}{l}\text { Age (years) } \\
\text { Sex (male) }\end{array}$ & 1.07 & $1.01-1.12$ & 0.022 & $40-87$ years \\
$\begin{array}{l}\text { Maximum IOP } \\
\text { (mmHg) }\end{array}$ & 1.07 & $0.96-12.70$ & 0.057 & N/A \\
\hline
\end{tabular}

the opportunity to enable clinical 'streaming' whereby high-risk patients could be identified and monitored closely, increasing quality of patient care, and low-risk patients could be seen less frequently without loss of care quality. This risk stratification approach provides potential for maintenance or possible improvement in quality of patient care, while also optimising the efficiency of service organisation. It is possible that many low-risk patients may currently be seen more often than necessary and therefore some time saving may be made, thus indirectly making staff and resources available for other clinical duties.

Although data are now available that strongly support the role of IOP control in reducing the rate of progressive loss of visual field in POAG, ${ }^{44,45}$ the existence of additional risk factors for progression in POAG from routine clinical data does not appear to have been fully explored, although a number of reports are available for normal tension glaucoma. ${ }^{18-21}$ In the recent past, prospective data have become available from the Early Manifest Glaucoma Trial (EMGT) on risk factors for progression of open-angle glaucoma (both normal tension of glaucoma (NTG) and POAG). ${ }^{24}$ However, because of limited evidence it remains uncertain as to whether differences exist between risk factors for initial development of POAG and for progression of glaucomatous damage. In clinical environments, routine data on optic nerve head structural appearance, visual field status, and IOP control provide the largest contributions to longitudinal review of patients diagnosed with POAG. This study has therefore attempted to identify additional factors from data routinely collected in clinical environments, primarily baseline characteristics, associated with increased risk of progressive visual field loss in treated POAG patients. We consider that this pragmatic approach is of value because it may be generalised to routine follow-up of POAG patients.

A number of observations have resulted from this work. It has been established that the incidence rate of visual field defect progression in the study cohort was approximately five cases per 100 person years, or $5 \%$ per year, with $19 \%$ of the cohort progressing over the average 
follow-up period of 3.6 years. Because of the study design, and for general ethical reasons, no untreated POAG data are available for comparison, and therefore data from the literature were sought in order to gauge whether this rate was typical. Data from the AGIS study revealed that between 10.9 and $15.1 \%$ of white POAG patients had progressed at 2 years according to differing treatment types. ${ }^{46}$ These comparative proportions suggest that the observed proportion of progressive cases among the cohort studied is broadly characteristic of a treated Caucasian POAG population. Of course, it should be noted that the proportion of individuals that progress is dependent upon the outcome criterion used. In this study the AGIS visual field defect score was chosen because it is widely recognised, has well-described measurement error, ${ }^{25}$ and may be easily deployed in clinical situations. However, it is important to be aware that the AGIS defect scoring system has been shown to perform conservatively relative to other methods for detection of visual field progression. ${ }^{26,27}$

It was found that one of the exposures considered as a candidate risk factor (see Table 2) was positively associated with progressive GVFD, with two further factors exhibiting a positive trend that was of borderline significance. Of these, increasing age was found to be associated with a significantly increased risk of visual field defect progression $(P=0.022)$, and this finding is in agreement with report from the EMGT. ${ }^{24}$ Age is a wellknown risk factor for initial development of glaucomatous nerve head changes and visual field defects $^{5,7,47-49}$ and intuitively, this finding was not surprising as physiologic age-related decline in ganglion cell number should be expected to produce gradual, if small, losses of visual function given sufficient time. Established glaucoma may therefore increase the proportion of cell death to pathophysiologic levels. It was also shown that being male or having higher levels of IOP at any time during the course of clinical review showed a weak positive relationship with visual field defect progression, although neither was found to be statistically significant at the $P<0.05$ level. The relationship between a high IOP measurement and visual field progression may be explained on the basis of loss of laminar integrity ${ }^{50-54}$ and it should again be noted that the EMGT also found higher baseline IOPs to be associated with increased risk of glaucomatous progression; ${ }^{24}$ however, it is more difficult to explain the weak association between progression and being male. It is tempting to speculate that this observation may reflect a greater susceptibility of males to cardiovascular risk factors in general or perhaps that males have a shorter life expectancy than females.

A further notable finding was that no association was demonstrated between level of IOP control and visual field defect progression in this study, in spite of reports to the contrary from prospectively collected data from a multicentre study with a large sample size ${ }^{44}$ and a randomised controlled trial. ${ }^{45}$ In our cohort, the average percentage IOP reduction was relatively high at $19.5 \%$, demonstrating a reasonable average level of IOP control for the entire cohort. It is therefore possible that this level of IOP reduction may have minimised any IOP effect on prognosis at the individual patient level, and this hypothesis may benefit from investigation using prospective cohort study designs. Previous studies that failed to identify a relationship between IOP reduction and lower risk of visual field defect progression suggested that the relationship between IOP and progression might not be simple. ${ }^{14}$ Rather than a linear relationship between visual field defect worsening and IOP control it is conceivable that individuals may have their own IOP damage thresholds with susceptibility to progressive damage determined by a variety of IOPindependent factors, perhaps including those identified in this study. Furthermore, it is also possible that our methodology, namely conservative choice of progression criterion or relatively short longitudinal review period, may have contributed to this negative finding.

Interestingly, the variables found to be associated with visual field defect progression in this study were not in complete agreement with findings reported by recent investigations attempting to answer similar questions. Stewart et $\mathrm{al}^{22}$ used a multicentre case-control study design to identify variables associated with a pragmatic clinical definition of progression based on change of either the optic disc or visual field. ${ }^{22}$ As with our study, increasing age was found to be associated with progression but associations were also demonstrated between progression and higher mean IOP during the follow-up, increased standard deviation of IOP during follow-up, and greater baseline CDR, none of which were identified in our investigation. Tezel et $a l^{23}$ used a retrospective approach that was similar to our experimental design, with a 5 year review period in an attempt to identify risk factors for glaucomatous change in neuroretinal rim area in aggressively treated POAG and NTG patients. This particular study used a strict case-definition applied to optic nerve head photographs, and concentrated upon optic nerve head features as potential risk factors for progression. Although age and sex were investigated, neither was found to be significantly associated with progressive glaucomatous optic nerve head signs. More recently, Leske et al $24,45,55$ have reported the results of the EMGT that used both optic head structure and visual field criteria for progression in both NTG and POAG. This randomised controlled trial (RCT) identified a number of treatmentindependent factors to be associated with progressive 
glaucoma including baseline higher IOP level, exfoliation, worse HFA mean deviation, and increasing age. Longitudinal assessment also revealed that disc haemorrhages and poorer IOP control were also associated with progression. It is most likely these studies identified differences in risk factors for progression to those found in our investigation because of variations in study design, specifically with regard to inclusion criteria and alternative case-definitions for glaucomatous progression in the form of progressive structural changes at the optic nerve head. Risk factors for structural change may differ from those for visual field change as described in our investigations: the exact temporal and spatial relationship between structural and functional damage in glaucoma remains unknown. ${ }^{56,57} \mathrm{It}$ should be also be stated that while data from the RCT design studies provide powerful information about disease, it is important to be aware that such explanatory RCT methodology is not completely generalisable to routine clinical situations due to highly structured follow-up, strict adherence to data collection protocols, greater staffing levels, enhanced and standardised staff training, and increased observer motivation. Bearing this in mind, it is also possible that the pragmatic nature of our cohort study did not permit the issue of patient compliance with treatment to be examined. It is important to recognise the disadvantages of retrospective cohort study design, which include inability to measure the effect of exposures other than those collected routinely, lack of measurement or diagnostic standardisation, and incomplete ascertainment of both exposures and outcomes.

Interpretation of data from this investigation should be made with the awareness of a number of caveats. Firstly, it should be highlighted only individuals with OAG in whom IOP was documented to exceed $22 \mathrm{mmHg}$ on at least one occasion (POAG) were studied. This approach was taken in part because this subgroup constitutes the largest proportion of individuals with chronic openangle glaucoma, ${ }^{5,48,49}$ but also because of the possible aetiological differences that may exist between this group and those patients whose IOPs never exceed this level. It should also be recognised that some selection bias may be present as diurnal IOP measurement was not performed as part of the routine clinical assessment and therefore a small number of subjects with POAG may have been misclassified as NTG was not included. The second important caveat relates to the number of cases of progression identified. It may be argued that data collected over the relatively short period studied may lack statistical power because relatively few cases of progressive glaucomatous visual field loss were identified in comparison with the number that could have been included in a case-control study. In answer to this, it should be observed that a cohort study design has the major advantage over a case-control approach because it provides information on progression incidence, which is of value in the context of health care organisation, in addition to determination of factors associated with progression. Furthermore, in conjunction with standardised clinical data collection, this study design avoids most sources of information and selection bias intrinsic to case-control study designs.

In summary, description of rates of progressive glaucoma and risk factors associated with glaucoma progression are important prognostically and may be valuable for health care service organisation. In a cohort of treated POAG patients receiving follow-up in a routine hospital eye service glaucoma clinic, the incidence of glaucomatous visual field progression was found to be approximately five cases per 100 person years of followup. Of a number of candidate variables investigated, increasing age was found to be significantly associated with progression, while being male and presence of higher levels of IOP at any time during follow-up demonstrated borderline trends. However, lack of agreement between risk factors for glaucomatous progression identified by this study and those from previous reports suggests that further prospective investigation of this issue is required.

\section{Acknowledgements}

Dr Spry would like to thank statistician Hazel Taylor of the Research and Development Support Unit, United Bristol Healthcare NHS Trust.

\section{References}

1 Hart Jr WM, Yablonski M, Kass MA, Becker B. Multivariate analysis of the risk of glaucomatous visual field loss. Arch Ophthalmol 1979; 97: 1455-1458.

2 Wilson MR, Hertzmark E, Walker AM, Childs-Shaw K, Epstein DL. A case-control study of risk factors in openangle glaucoma. Arch Ophthalmol 1987; 105: 1066-1071.

3 Katz J, Sommer A. Risk factors for primary open-angle glaucoma. Am J Prev Med 1988; 4: 110-114.

4 Sommer A, Tielsch JM, Katz J, Quigley HA, Gottsch JD, Javitt J. Relationship between intraocular pressure and primary open-angle glaucoma among white and black Americans. The Baltimore Eye Survey. Arch Ophthalmol 1991; 109: 1090-1095.

5 Klein BE, Klein R, Sponsel WE, Franke T, Cantor LB, Martone J. Prevalence of glaucoma. The Beaver Dam Eye Study. Ophthalmology 1992; 99: 1499-1504.

6 Klein BE, Klein R, Meuer SM, Goetz LA. Migraine headache and its association with open-angle glaucoma: the Beaver Dam Eye Study. Invest Ophthalmol Vis Sci 1993; 34: 3024-3027.

7 Quigley HA, Enger C, Katz J, Sommer A, Scott R, Gilbert D. Risk factors for the development of glaucomatous visual 
field loss in ocular hypertension. Arch Ophthalmol 1994; 112: 644-649.

8 Tielsch JM, Katz J, Quigley HA, Javitt JC, Sommer A. Diabetes, intraocular pressure, and primary open-angle glaucoma in the Baltimore Eye Survey. Ophthalmology 1995; 102: 48-53.

9 Drance SM. The glaucomatous visual field defect. $\mathrm{Br} J$ Ophthalmol 1972; 56: 182-200.

10 Aulhorn E, Karmeyer H. Frequency distribution of early glaucomatous visual field defects. Doc Ophthalmol Proc Ser 1977; 14: 75-83.

11 Werner EB, Drance SM. Increased scatter of responses as a precursor of visual field changes in glaucoma. Can J Ophthalmol 1977; 12: 140-142.

12 Johnson CA, Adams AJ, Casson EJ, Brandt JD. Blue-onyellow perimetry can predict the development of glaucomatous visual field loss. Arch Ophthalmol 1993; 111: 645-650.

13 Chauhan BC, Tompkins JD, LeBlanc RP, McCormick TA. Characteristics of frequency-of-seeing curves in normal subjects, patients with suspected glaucoma, and patients with glaucoma. Invest Ophthalmol Vis Sci 1993; 34: 3534-3540.

14 Drance S, Anderson DR, Schulzer M. Risk factors for progression of visual field abnormalities in normal-tension glaucoma. Am J Ophthalmol 2001; 131: 699-708.

15 Crick RP, Daubs JG. Epidemiological aids to clinical decision making in primary open-angle glaucoma. Int Ophthalmol 1980; 3: 37-41.

16 Harper RA, Reeves BC. Glaucoma screening: the importance of combining test data. Optom Vis Sci 1999; 76: 537-543.

17 Spencer IC. How do we manage chronic open-angle glaucoma? A validation study in the south-west region of Britain. M.Sc thesis. University of Bristol, 1992.

18 Ishida K, Yamamoto T, Kitazawa Y. Clinical factors associated with progression of normal-tension glaucoma. J Glaucoma 1998; 7: 372-377.

19 Daugeliene L, Yamamoto T, Kitazawa Y. Risk factors for visual field damage progression in normal-tension glaucoma eyes. Graefes Arch Clin Exp Ophthalmol 1999; 237: 105-108.

20 Fontana L, Armas R, Garway-Heath DF, Bunce CV, Poinoosawmy D, Hitchings RA. Clinical factors influencing the visual prognosis of the fellow eyes of normal tension glaucoma patients with unilateral field loss. $\mathrm{Br} J$ Ophthalmol 1999; 83: 1002-1005.

21 Membrey WL, Poinoosawmy DP, Bunce C, Fitzke FW, Hitchings RA. Comparison of visual field progression in patients with normal pressure glaucoma between eyes with and without visual field loss that threatens fixation. $\mathrm{Br} J$ Ophthalmol 2000; 84: 1154-1158.

22 Stewart WC, Kolker AE, Sharpe ED, Day DG, Holmes KT, Leech JN. Factors associated with long-term progression or stability in primary open-angle glaucoma. Am J Ophthalmol 2000; 130: 274-279.

23 Tezel G, Siegmund KD, Trinkaus K, Wax MB, Kass MA, Kolker AE. Clinical factors associated with progression of glaucomatous optic disc damage in treated patients. Arch Ophthalmol 2001; 119: 813-818.

24 Leske MC, Heijl A, Hussein M, Bengtsson B, Hyman L, Komaroff E. Factors for glaucoma progression and the effect of treatment: the early manifest glaucoma trial. Arch Ophthalmol 2003; 121: 48-56.
25 Advanced Glaucoma Intervention Study (AGIS) Investigators. Visual field test scoring and reliability. . Ophthalmology 1994; 101: 1445-1455.

26 Katz J. Scoring systems for measuring progression of visual field loss in clinical trials of glaucoma treatment. Ophthalmology 1999; 106: 391-395.

27 Katz J, Congdon N, Friedman DS. Methodological variations in estimating apparent progressive visual field loss in clinical trials of glaucoma treatment. Arch Ophthalmol 1999; 117: 1137-1142.

28 Wood JM, Wild JM, Hussey MK, Crews SJ. Serial examination of the normal visual field using Octopus automated projection perimetry. Evidence for a learning effect. Acta Ophthalmologica 1987; 65: 326-333.

29 Becker B. Diabetes mellitus and primary open-angle glaucoma. The XXVII Edward Jackson Memorial Lecture. Am J Ophthalmol 1971; 1: 1-16.

30 Morgan RW, Drance SM. Chronic open-angle glaucoma and ocular hypertension. An epidemiological study. $\mathrm{Br} J$ Ophthalmol 1975; 59: 211-215.

31 Daubs JG, Crick RP. Effect of refractive error on the risk of ocular hypertension and open-angle glaucoma. Trans Ophthalmol Soc UK 1981; 101: 121-126.

32 Perkins ES, Phelps CD. Open-angle glaucoma, ocular hypertension, low-tension glaucoma, and refraction. Arch Ophthalmol 1982; 100: 1464-1467.

33 Phelps CD. Effect of myopia on prognosis in treated primary open-angle glaucoma. Am J Ophthalmol 1982; 93: 622-628.

34 Klein BE, Klein R, Moss SE. Intraocular pressure in diabetic persons. Ophthalmology 1984; 91: 1356-1360.

35 Martin MJ, Sommer A, Gold EB, Diamond EL. Race and primary open-angle glaucoma. Am J Ophthalmol 1985; 99: 383-387.

36 Phelps CD, Corbett JJ. Migraine and low-tension glaucoma. A case-control study. Invest Ophthalmol Vis Sci 1985; 26: 1105-1108.

37 Drance SM, Douglas GR, Wijsman K, Schulzer M, Britton RJ. Response of blood flow to warm and cold in normal and low-tension glaucoma patients. Am J Ophthalmol 1988; 105 35-39.

38 Drance SM. Disc hemorrhages in the glaucomas. Surv Ophthalmol 1989; 33: 331-337.

39 Tielsch JM, Sommer A, Katz J, Royall RM, Quigely HA, Javitt J. Racial variations in the prevalence of primary openangle glaucoma. The Baltimore Eye Survey. JAMA 1991; 266: 369-374.

40 Tielsch JM, Katz J, Sommer A, Quigley HA, Javitt JC. Family history and risk of primary open-angle glaucoma. The Baltimore Eye Survey. Arch Ophthalmol 1994; 112: 69-73.

41 Wormald RP, Basauri E, Wright LA, Evans JR. The African Caribbean Eye Survey: risk factors for glaucoma in a sample of African Caribbean people living in London. Eye 1994; 8: 315-320.

42 McKendrick AM, Vingrys AJ, Badcock DR, Heywood JT. Visual dysfunction between migraine events. Invest Ophthalmol Vis Sci 2001; 42: 626-633.

43 Grambsch P, Therneau T. Proportional hazards tests and diagnostics based on weighted residuals. Biometrika 1994; 81: 515-526.

44 Investigators A. The advanced glaucoma intervention study (AGIS): 7. The relationship between control of intraocular 
pressure and visual field deterioration. Am I Ophthalmol 2000; 130: $429-440$.

45 Heijl A, Leske MC, Bengtsson B, Hyman L, Hussein M. Reduction of intraocular pressure and glaucoma progression: results from the Early Manifest Glaucoma Trial. Arch Ophthalmol 2002; 120: 1268-1279.

46 The Advanced Glaucoma Intervention Study (AGIS): 4. Comparison of treatment outcomes within race. Seven-year results. Ophthalmology 1998; 105: 1146-1164.

47 Armaly MF, Krueger DE, Maunder L, Becker B, Hetherington Jr J, Kolker AE. Biostatistical analysis of the collaborative glaucoma study. I. Summary report of the risk factors for glaucomatous visual-field defects. Arch Ophthalmol 1980; 98: 2163-2171.

48 Coffey M, Reidy A, Wormald R, Xian WX, Wright L, Courtney P. Prevalence of glaucoma in the west of Ireland. Br J Ophthalmol 1993; 77: 17-21.

49 Dielemans I, Vingerling JR, Wolfs RC, Hofman A, Grobbee $\mathrm{DE}$, de Jong PT. The prevalence of primary open-angle glaucoma in a population-based study in The Netherlands. The Rotterdam Study. Ophthalmology 1994; 101: 1851-1855.

50 Hernandez MR, Andrzejewska WM, Neufeld AH. Changes in the extracellular matrix of the human optic nerve head in primary open-angle glaucoma. Am J Ophthalmol 1990; 109: 180-188.
51 Varela HJ, Hernandez MR. Astrocyte responses in human optic nerve head with primary open-angle glaucoma. $J$ Glaucoma 1997; 6: 303-313.

52 Pena JD, Netland PA, Vidal I, Dorr DA, Rasky A, Hernandez MR. Elastosis of the lamina cribrosa in glaucomatous optic neuropathy. Exp Eye Res 1998; 67: 517-524.

53 Hernandez MR. The optic nerve head in glaucoma: role of astrocytes in tissue remodeling. Prog Retin Eye Res 2000; 19: 297-321.

54 Pena JD, Agapova O, Gabelt BT, Levin LA, Lucarelli MJ, Kaufman PL. Increased elastin expression in astrocytes of the lamina cribrosa in response to elevated intraocular pressure. Invest Ophthalmol Vis Sci 2001; 42: 2303-2314.

55 Leske MC, Heijl A, Hyman L, Bengtsson B. Early Manifest Glaucoma Trial: design and baseline data. Ophthalmology 1999; 106: 2144-2153.

56 Cioffi GA, Liebmann JM, Johnson CA, Weinreb RN. Structural-functional relationships of the optic nerve in glaucoma. J Glaucoma 2000; 9: 3-4.

57 Johnson CA, Cioffi GA, Liebmann JM, Sample PA, Zangwill LM, Weinreb RN. The relationship between structural and functional alterations in glaucoma: a review. Semin Ophthalmol 2000; 15: 221-233. 